\title{
Forecasting the incidence of mumps in Chongqing based on a SARIMA model
}

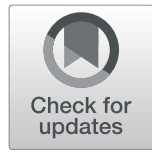

Hongfang Qiu ${ }^{1}$, Han Zhao ${ }^{2}$, Haiyan Xiang ${ }^{1}$, Rong Ou ${ }^{3}$, Jing Yi ${ }^{1}$, Ling Hu${ }^{1}$, Hua Zhu ${ }^{1}$ and Mengliang Ye ${ }^{1^{*}}$

\begin{abstract}
Background: Mumps is classified as a class C infection disease in China, and the Chongqing area has one of the highest incidence rates in the country. We aimed to establish a prediction model for mumps in Chongqing and analyze its seasonality, which is important for risk analysis and allocation of resources in the health sector.

Methods: Data on incidence of mumps from January 2004 to December 2018 were obtained from Chongqing Municipal Bureau of Disease Control and Prevention. The incidence of mumps from 2004 to 2017 was fitted using a seasonal autoregressive comprehensive moving average (SARIMA) model. The root mean square error (RMSE) and mean absolute percentage error (MAPE) were used to compare the goodness of fit of the models. The 2018 incidence data were used for validation.

Results: From 2004 to 2018, a total of 159,181 cases (93,655 males and 65,526 females) of mumps were reported in Chongqing, with significantly more men than women. The age group of 0-19 years old accounted for $92.41 \%$ of all reported cases, and students made up the largest proportion (62.83\%), followed by scattered children and children in kindergarten. The SARIMA $(2,1,1) \times(0,1,1)_{12}$ was the best fit model, RMSE and MAPE were 0.9950 and 39.8396\%, respectively.

Conclusion: Based on the study findings, the incidence of mumps in Chongqing has an obvious seasonal trend, and SARIMA $(2,1,1) \times(0,1,1)_{12}$ model can also predict the incidence of mumps well. The SARIMA model of time series analysis is a feasible and simple method for predicting mumps in Chongqing.
\end{abstract}

Keywords: Incidence, Mumps, SARIMA model, Chongqing

\section{Background}

Mumps is a disease caused by an infection due to mumps virus. It is a vaccine-preventable toxic disease in children [1], and the main population affected is children and adolescents [2]. The clinical manifestation of mumps virus infection is pain and swelling of the parotid gland, but it may also affect various tissues and organs [3]. It can also cause serious complications, such as encephalitis, meningitis, orchitis, myocarditis, pancreatitis, and nephritis [3, 4]. Patients generally recover spontaneously within a few moments of infection, but

* Correspondence: yemengliang@cqmu.edu.cn

${ }^{1}$ Department of Epidemiology and Health Statistics, School of Public Health and Management, Chongqing Medical University, Chongqing 400016, China Full list of author information is available at the end of the article the disease has long-term consequences, such as seizures, cerebral palsy, hydrocephalus and deafness $[4,5]$. Mumps is a global epidemic [6], with outbreaks occurring in several regions, such as Ireland [7], Nebraska [8], and Arkansas [9]. The incidence of mumps in China is high [10].

In 2018, China had the highest number of cases in the world (259,071 cases), followed by Nepal $(29,614$ cases) and Burkina Faso (26,982 cases) [11]. From 2004 to 2018 , China reported $4,272,368$ cases, and the average incidence was 2144 per 100,000 per year [12]. In 1990, mumps was included in the management of class $C$ infectious diseases (class $C$ infectious diseases are known as surveillance and management infectious diseases, including filariasis, hydatid disease, leprosy,

C C The Author(s). 2021 Open Access This article is licensed under a Creative Commons Attribution 4.0 International License, which permits use, sharing, adaptation, distribution and reproduction in any medium or format, as long as you give appropriate credit to the original author(s) and the source, provide a link to the Creative Commons licence, and indicate if changes were made. The images or other third party material in this article are included in the article's Creative Commons licence, unless indicated otherwise in a credit line to the material. If material is not included in the article's Creative Commons licence and your intended use is not permitted by statutory regulation or exceeds the permitted use, you will need to obtain permission directly from the copyright holder. To view a copy of this licence, visit http://creativecommons.org/licenses/by/4.0/ The Creative Commons Public Domain Dedication waiver (http://creativecommons.org/publicdomain/zero/1.0/) applies to the data made available in this article, unless otherwise stated in a credit line to the data. 
influenza, mumps, epidemic and endemic typhus, rubella, acute hemorrhagic conjunctivitis, hand, foot and mouth disease, and infectious diarrhoeal diseases other than amoebic dysentery, typhoid and paratyphoid, etc.) [13]. Mumps-containing vaccines were included in the expanded national immunization program in 2008 [14]. From 2014 to 2016, the reported incidence of mumps began to decline nationwide, but rose again in 2017 and 2018 [12]. Mumps is highly contagious and often causes outbreaks in school nurseries and other collective units, seriously affecting the normal school teaching order. Mumps is one of the important public health problems that endanger the physical and mental health of children and adolescents in China [15]. Thus, understanding the epidemic regularity and predicting the epidemic trend of mumps is crucial for risk analysis and health resource allocation in the health sector.

Time series analysis is a scientific quantitative prediction of the future trend of diseases based on historical data and time variables. It is a quantitative analysis method that does not consider the influence of complex factors [16]. The ARIMA model is one of the most representative and widely used models in time series prediction [17], and this method is simple and requires only endogenous variables instead of other exogenous variables. In epidemiological studies, the ARIMA model has been used in many studies, such as malaria [18], tuberculosis [19, 20], dengue [21] and other diseases [22, 23]. To the best of our knowledge, Chongqing is one of the areas with the highest incidence rates in China [24]. Furthermore,
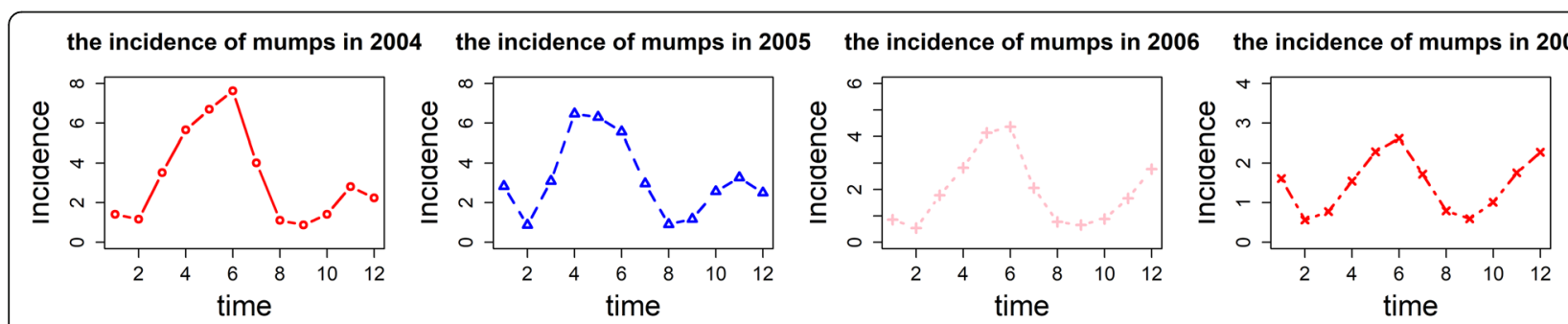

the incidence of mumps in 2008

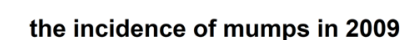

the incidence of mumps in $\mathbf{2 0 1 0}$
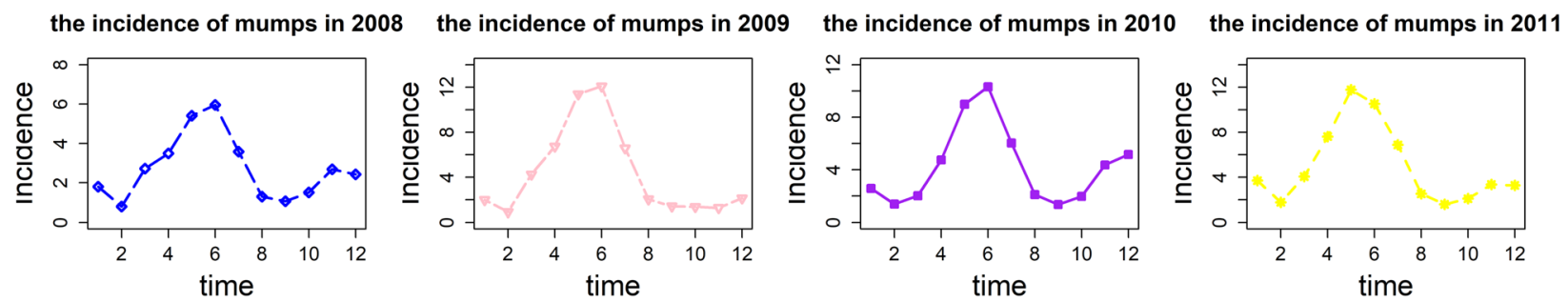

the incidence of mumps in 2012

the incidence of mumps in 2013

the incidence of mumps in 2014

the incidence of mumps in 2015
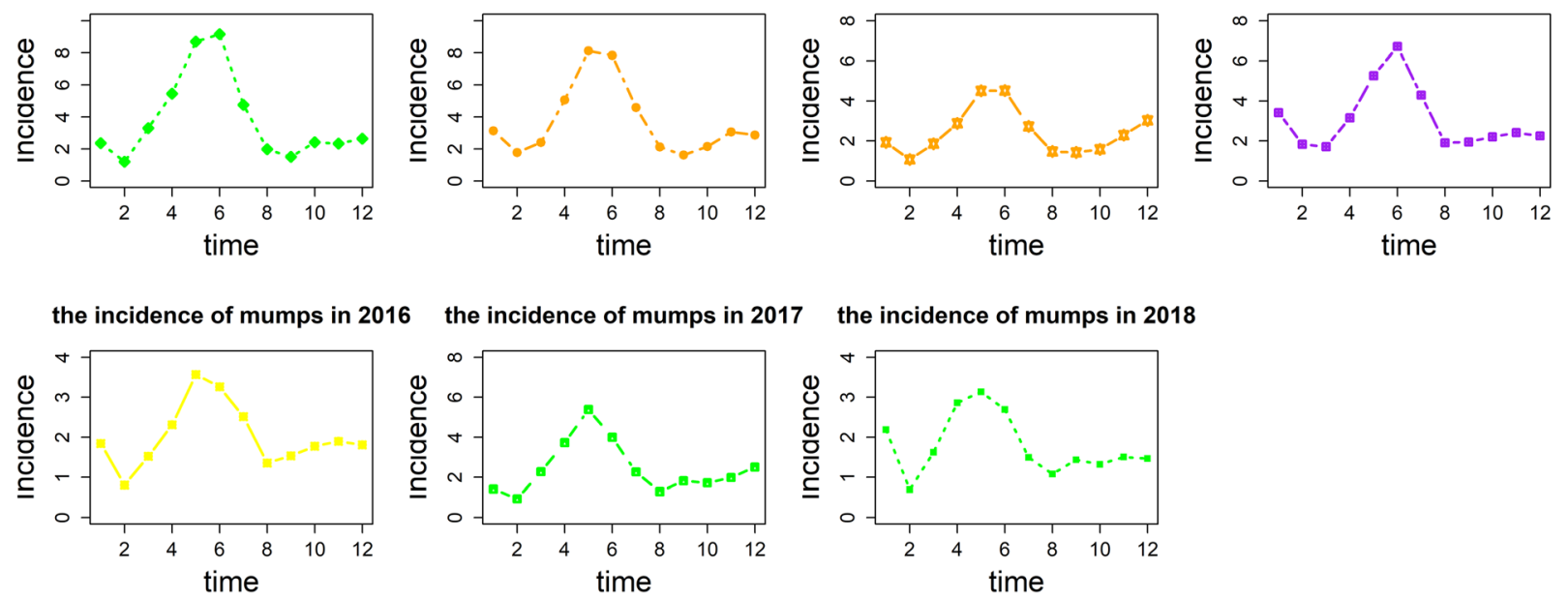

Fig. 1 Monthly incidence of mumps from 2004 to 2018 in Chongqing 
no previous research has been conducted to predict the incidence of mumps in Chongqing. To address these noted gaps, this paper is the first to establish a time series analysis of the mumps incidence data for short-term prediction in Chongqing. We developed a seasonal autoregressive comprehensive moving average (SARIMA) model to forecast the incidence of mumps. As we all know, the SARIMA model has one more seasonal effect than the ARIMA model, and it is generally handled by seasonal difference [25]. The results of this study may be useful for predicting mumps epidemics and offer reference information for mumps control and intervention in Chongqing.

\section{Methods}

\section{Data collection}

In this study, mumps data from 2004 to 2018 were collected from Chongqing CDC. All cases in each region were verified through clinical and laboratory diagnosis, and reported to the CDC by the health department. The reported data includes the sex, occupation, age and region of the patient. The data were finally collected from each region and submitted to the Chongqing CDC.

\section{SARIMA model construction}

SARIMA differs from ARIMA models in that it contains seasonal characteristics of time series [26], and is an extension of ARIMA model. The general structure of SARI MA model is expressed as SARIMA $(\mathrm{p}, \mathrm{d}, \mathrm{q}) \times(\mathrm{P}, \mathrm{D}$, $\mathrm{Q})_{S}$, and its formula is as follows [27]:

$$
\begin{aligned}
& \nabla^{d} \nabla_{S}^{D} x_{t}=\frac{\Theta(B) \Theta_{S}(B)}{\Phi(B) \Phi_{S}(B)} \varepsilon_{t} \\
& \Theta(B)=1-\theta_{1} B-g g g-\theta_{q} B^{q} \\
& \Phi(B)=1-\phi_{1} B-g g g-\phi_{p} B^{p} \\
& \Theta_{S}(B)=1-\theta_{1} B^{S}-g g g-\theta_{Q} B^{Q S} \\
& \Phi_{S}(B)=1-\phi_{1} B^{S}-g g g-\phi_{P} B^{P S}
\end{aligned}
$$

In the above equation, $B$ represents the backward shift operator, $\varepsilon_{t}$ denotes the residual at time $\mathrm{t}$, the mean of $\varepsilon_{t}$ is zero and the variance of $\varepsilon_{t}$ is constant, $x_{t}$ is the observed value at time $\mathrm{t}(\mathrm{t}=1,2 \ldots \mathrm{k})$. In SARIMA $(p, d, q)$ $\times(P, D, Q)_{S}, \mathrm{~s}$ is the length of the seasonal period, $\mathrm{p}, \mathrm{P}$, $\mathrm{d}, \mathrm{D}, \mathrm{q}$ and $\mathrm{Q}$ are the autoregressive order, seasonal autoregressive order, number of difference, number of seasonal difference, moving average order and seasonal moving average order, respectively [27]. According to the sequence autocorrelation function (ACF) and partial autocorrelation function (PACF) for determining the values of the six parameters in the SARIMA model. Akaike information criterion (AIC) and Schwarz Bayesian Criterion (BIC) are two indexes of model optimization. A small AIC shows that is the better fitting model [26].

\begin{tabular}{|c|c|c|c|c|c|}
\hline Time & No 1 & No 2 & No 3 & No 4 & No 5 \\
\hline 2004 & Changshou District & Jiulongpo District & Hechuan & Nanan District & Yubei District \\
\hline 2005 & Jiangjin District & Hechuan & Kaixian & Fuling District & Wanzhou District \\
\hline 2006 & Nanchuan & Banan District & Shapingba District & Fengdu & Beibei District \\
\hline 2007 & Shapingba District & Beibei District & Dianjiang & Yunyang & Tongnan \\
\hline 2008 & Wanshneg District & Dianjiang & Shapingba District & Jiangjin District & Kaixian \\
\hline 2009 & Kaixian & Wanzhou District & Jiangjin District & Hechuan & Jiulongpo District \\
\hline 2010 & Wanzhou District & Jiulongpo District & Yongchuan District & Yunyang & Yubei District \\
\hline 2011 & Changshou District & Dainjiang & Beibei District & Jiulongpo District & Yubei District \\
\hline 2012 & Wushan & Yubei District & Jiulongpo District & Miao-Tujia Autonomous County of Pengshui & Shapingba District \\
\hline 2013 & Kaixian & Wanzhou District & Jiangjin District & liangping & Shapingba District \\
\hline 2014 & Wanzhou District & Zhongxian & Nanan District & Shapingba District & Kaixian \\
\hline 2015 & Yubei District & Nanan District & Changshou District & Yongchuan District & Hechuan \\
\hline 2016 & Yubei District & Dazu District & Wulong & Yongchuan District & Jiangjin District \\
\hline 2017 & Jiangjin District & Jiulongpo District & Yubei District & Nanan District & Tongliang \\
\hline 2018 & Jiulongpo District & Yubei District & Nanan District & Yongchuan District & Shapingba District \\
\hline
\end{tabular}

Finally, two indexes were used to compare the fitting effect. The formulas for RMSE and MAPE are [28]:

$$
\begin{aligned}
& \text { RMSE }=\sqrt{\frac{1}{n} \sum_{t=1}^{n}\left(x_{t}-\hat{x}_{t}\right)^{2}} \\
& M A P E=\frac{1}{n} \sum_{t=1}^{n} \frac{\left|x_{t}-x_{t}^{\wedge}\right|}{x_{t}}
\end{aligned}
$$

Table 1 The top five regions with more mumps cases each year in Chongqing from 2004 to 2018 


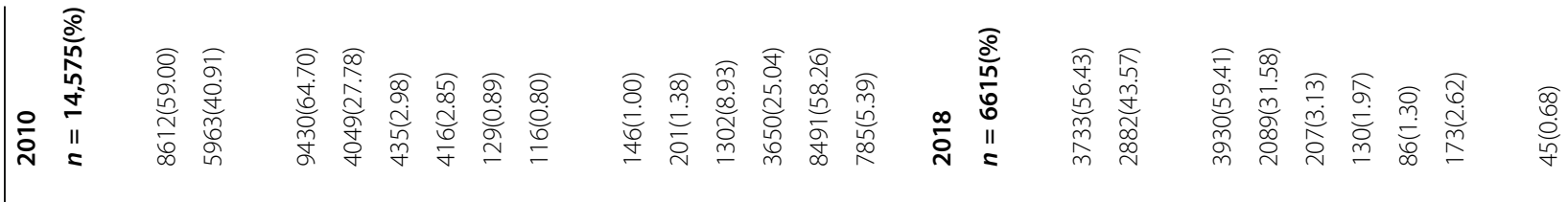

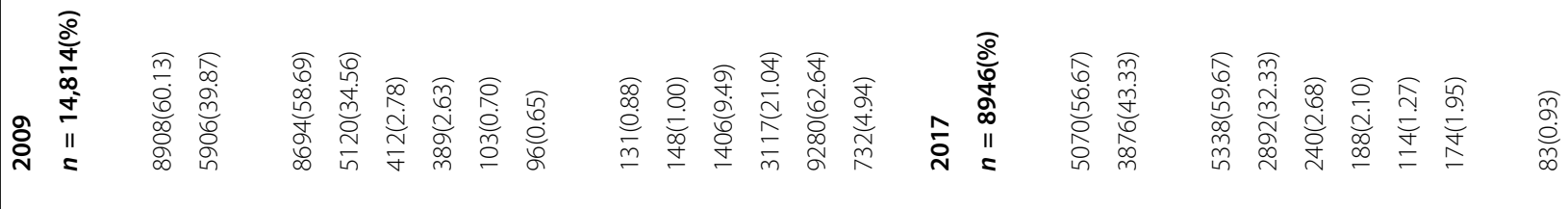

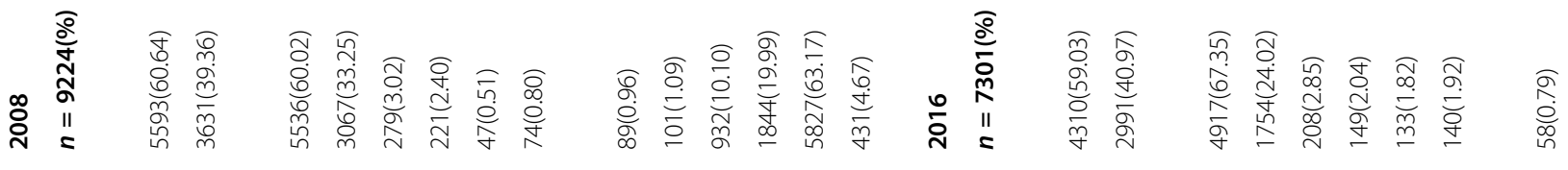

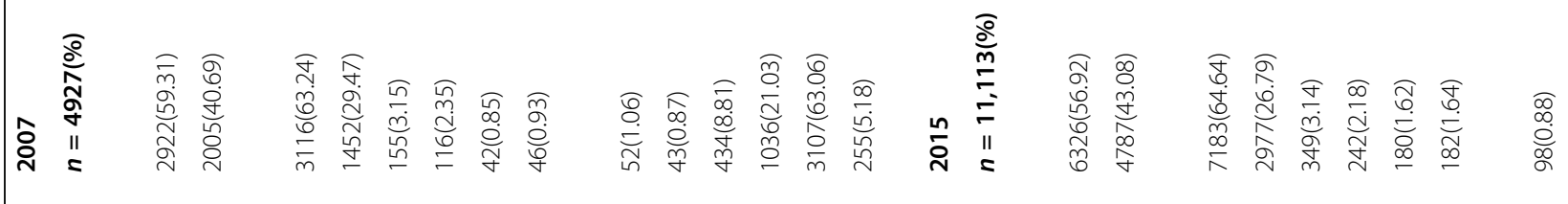

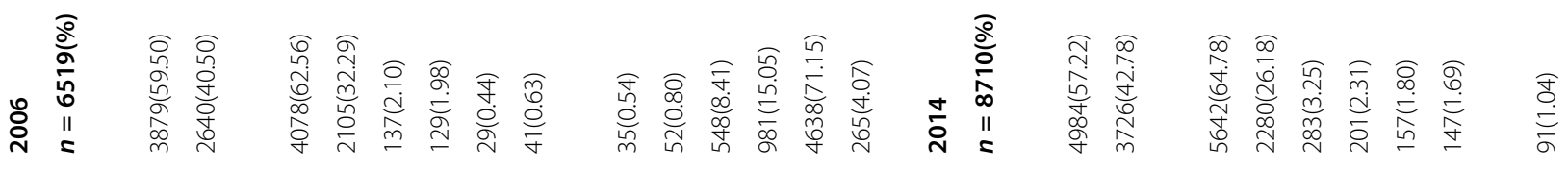

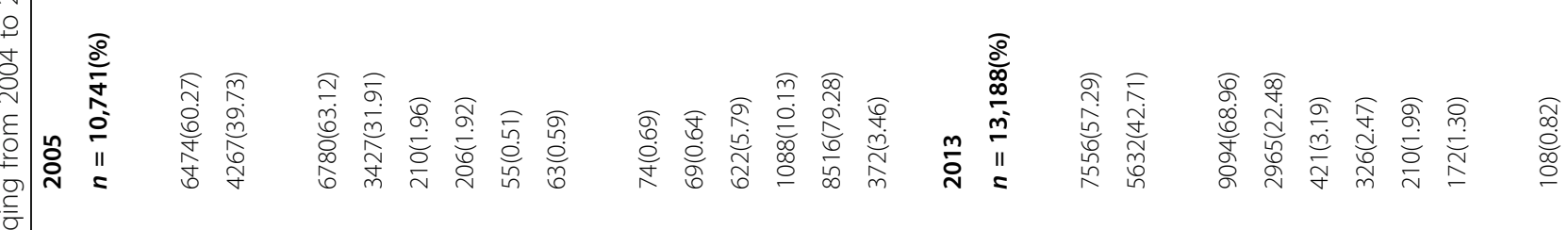

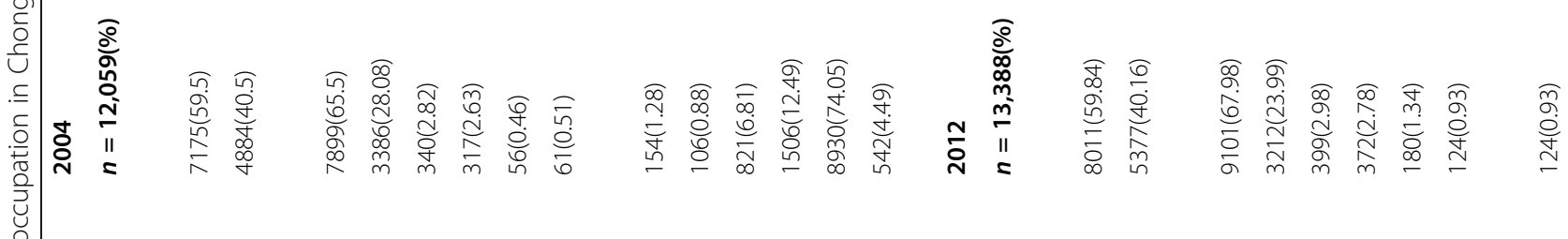

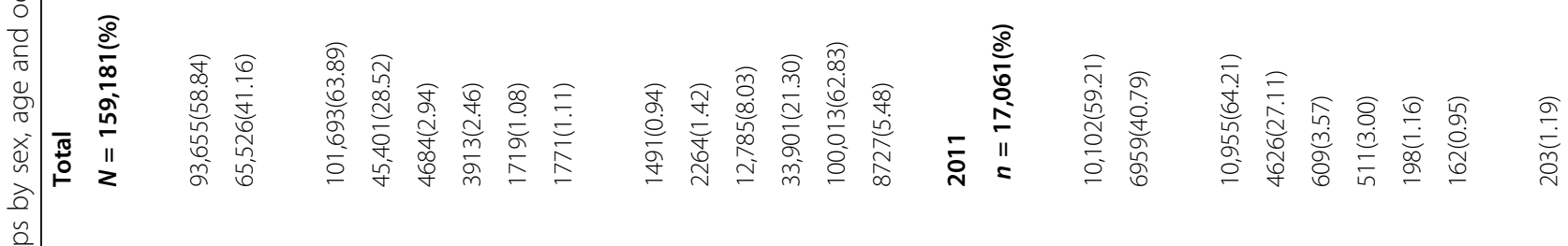

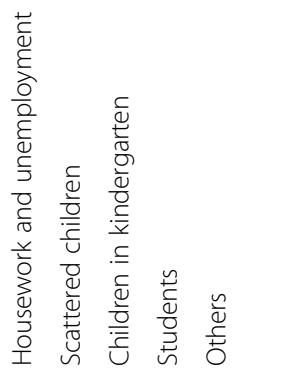

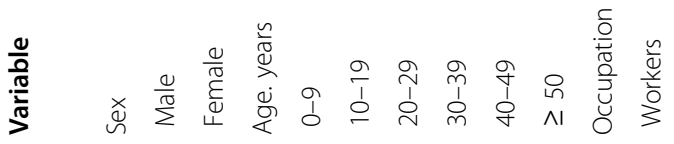




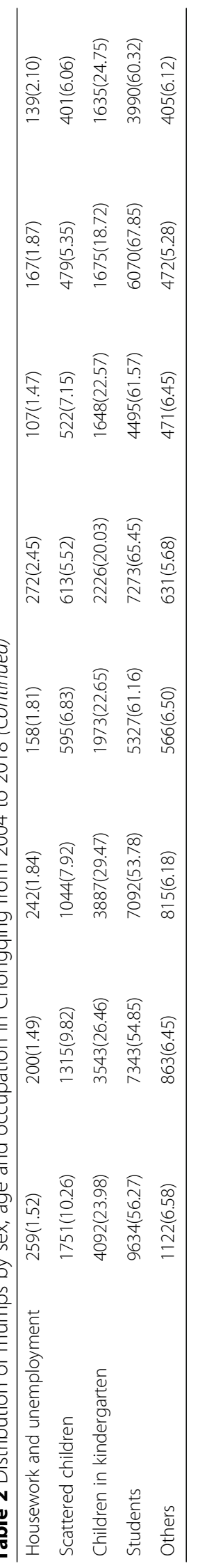




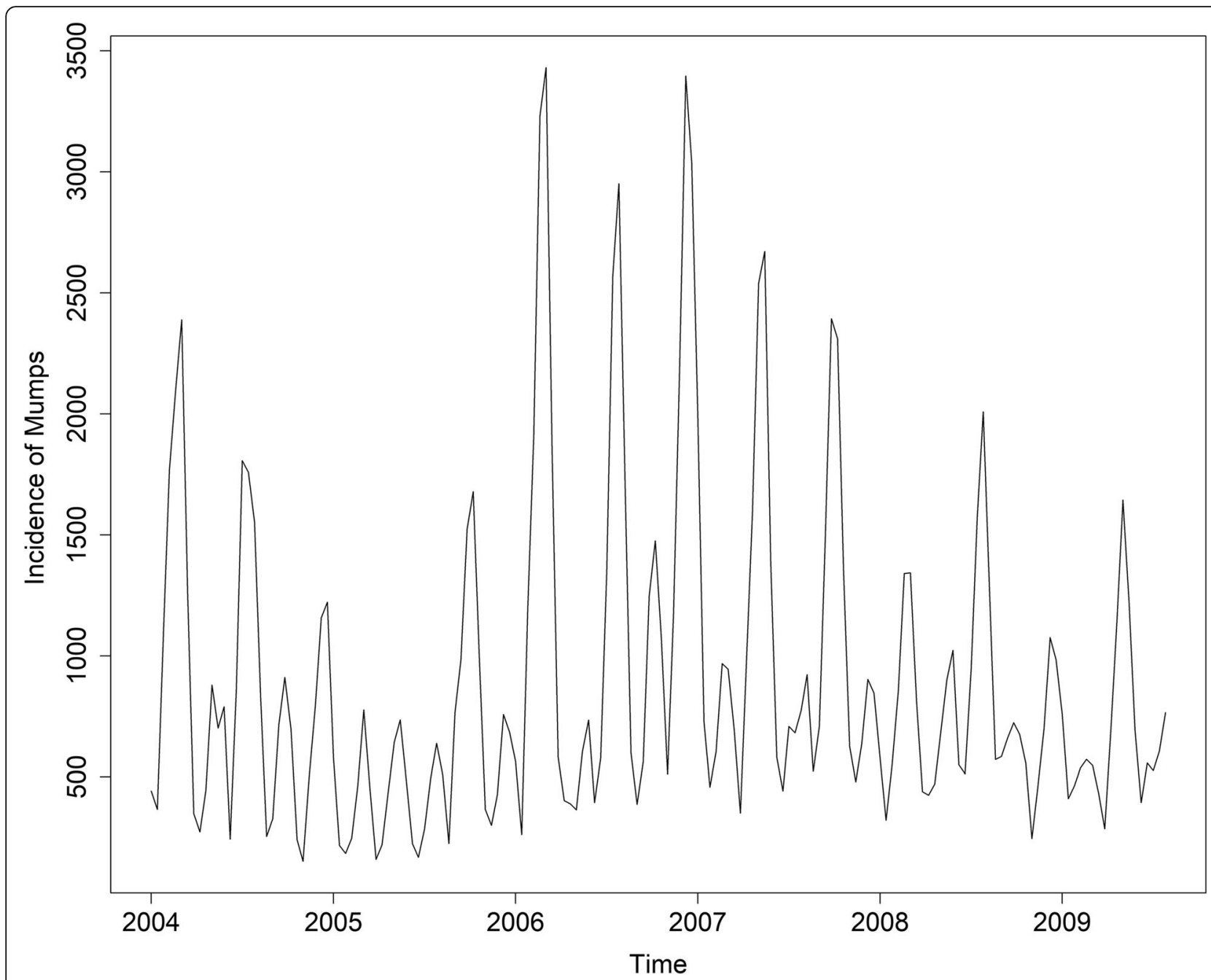

Fig. 2 Reported monthly incidence of mumps from January 2004 to December 2017

In the above equation, $x_{t}$ is the actual incidence value, $x_{t}^{\wedge}$ is the estimated incidence value, $\mathrm{n}$ is the number of months for forecasting. The lower RMSE and MAPE value, the better the data fitting effect.

\section{Statistical analysis}

Firstly, we used Excel 2010 to conduct a descriptive analysis of mumps in Chongqing from 2004 to 2018, and explain the sex, age, and occupational distribution of the disease onset. Secondly, the time series analysis of the mumps incidence sequence was analyzed. The "stl" function in the R 3.5.0 software was used to decompose the seasonal trend of the sequence. Finally, under the operation of the R3.5.0 software, a SARIMA model was established to predict the incidence of mumps. In this study, the incidence of mumps from 2004 to 2017 was used as a training dataset to fit the SARIMA model, predict the incidence of mumps in 2018, and verify the predicted effect. The significance level was $p<0.05$.

\section{Results}

The monthly incidence of mumps number is presented in Fig. 1, showing that monthly mumps incidence was low in February and peaked in April to July. Table 1 shows the top five regions with the highest number of mumps in Chongqing in the past 15 years. Although the location of Chongqing has changed, it is mainly concentrated in the northeast and west of Chongqing. Table 2 shows reported 159,181 mumps cases in the past 15 years (20042018), in Chongqing, The cases included 93,655 males and 65,526 females (male-to-female ratio of 1.43:1), with mumps commonly occurring between the ages of 0 and 19, and the age group of $0-19$ years accounted for the $92.41 \%(n=147,094)$ of all reported cases. The group with the highest proportion of mumps is students, amount to $62.83 \%(n=$ 100,013), followed by scattered children and children in kindergarten. 


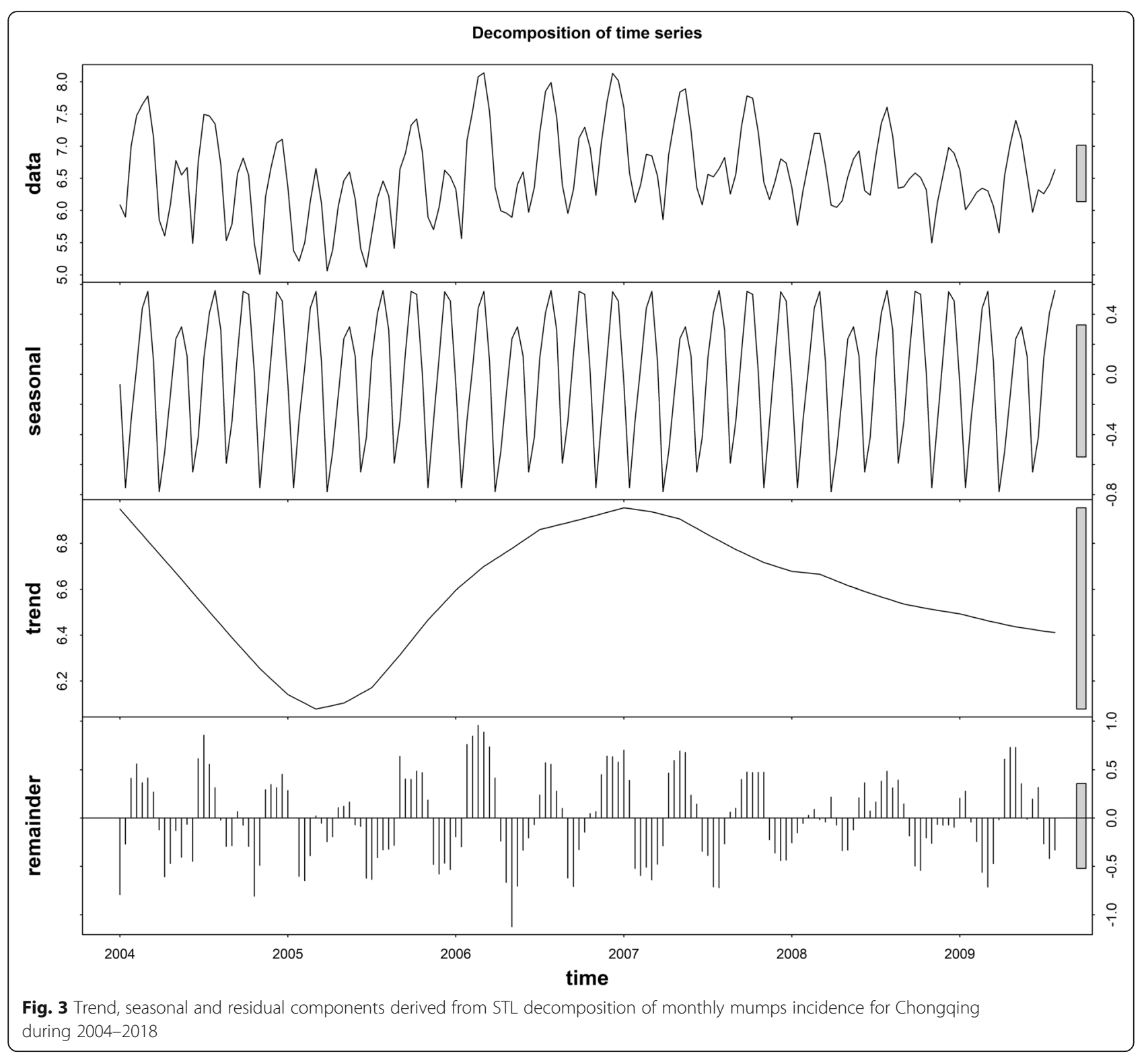

SARIMA $(p, d, q) \times(P, D, Q)_{s}$ model

Figure 2 shows the sequence diagram of mumps, and the sequence is nonstationary. Furthermore, the monthly incidence of mumps in Chongqing suggested a slightly decreasing tendency and seasonal tendency. Figure 3 shows the decomposition diagram of the sequence, with an obvious seasonality. After the natural logarithm transformation of the original data, a one-step difference and seasonal difference with a period of 12 was conducted to remove nonstationarity. The sequence diagram after the difference was stationary (Fig. 4), and the ADF test results showed that the sequence was stationary $(p<0.05)$. Figure 5 shows that $\mathrm{ACF}$ and PACF of the sequence were both trailing. Considering that the value of $\mathrm{p}, \mathrm{q}, \mathrm{P}$ and Q generally does not exceed 2, a trial order from 0 to 2 was performed. Only five models passed the test and the model parameter test: $\operatorname{SARIMA}(1,1,1) \times(1,1,0)_{12}$, SARI $\operatorname{MA}(0,1,2) \times(1,1,0)_{12}, \operatorname{SARIMA}(1,1,1) \times(0,1,1)_{12}$, $\operatorname{SARIMA}(2,1,1) \times(0,1,1)_{12}, \operatorname{SARIMA}(1,1,2) \times(0,1$, $1)_{12}$. The AIC, BIC values, and two error indicators of the five models were compared in Table 3 . And the SARI $\operatorname{MA}(2,1,1) \times(0,1,1)_{12}$ model was selected as the best one.

Table 4 shows the estimated and standard errors of model parameters and their corresponding significance values. The model equation is given as

$$
\nabla \nabla^{12} x_{t}=\frac{1-0.8197 B}{1-0.7186 B+0.2305 B^{2}}\left(1-0.7643 B^{12}\right) \varepsilon_{t}, \varepsilon_{t} \sim N(0,0.062)
$$






Fig. 4 Sequence diagram after a 1-step difference and seasonal difference with a period of 12

The $\operatorname{SARIMA}(2,1,1) \times(0,1,1)_{12}$ model was used to forecast the incidence of mumps in 2018. Table 5 shows the value of prediction, RMSE and MAPE values are 0.9950 and $39.8396 \%$, respectively. The actual value of incidence and fitted incidence of SARIMA model monthly are shown in Fig. 6 . Figure 6 and Table 5 show that the tendency and epidemics from predicted incidence are close to actual value of incidence and epidemic circumstance of mumps.

\section{Discussion}

In this study, we found that the annual incidence of mumps decreased significantly from 2004 to 2007 and increased from 2007 to 2011 . The lowest incidence was in $2007(175,463 / 100000)$ and the highest was in 2011 (591,471/100000). In the 159,181 reported cases, males were 1.43 times as many as females. These findings are consistent with the results of relevant literature [29]. In terms of age and occupation, the largest proportion of mumps cases were $0-19$ years old (92.41\%) and students (62.83\%), indicating that children and students are the main targets of protection. In addition, this study shows that the western and northeastern of Chongqing are high-incidence areas (Table 1). Therefore, the government should strengthen the prevention and control measures of mumps in important areas and populations.

We decomposed the mumps incidence sequence and found that the mumps incidence sequence had obvious trends and seasonality, the monthly incidence of mumps was low in February and peak in April to July, which was consistent with previous studies [10,30]. Therefore, taking some interventions are necessary to reduce the spread of infectious diseases in public transportation from April to July.

The results of this study indicate that model SARI $M A(2,1,1) \times(0,1,1)_{12}$ is the best predictive model. Figure 6 shows the 95\% CIs of the forecast value in this paper containing all of the real observed data, which is a 
(a)

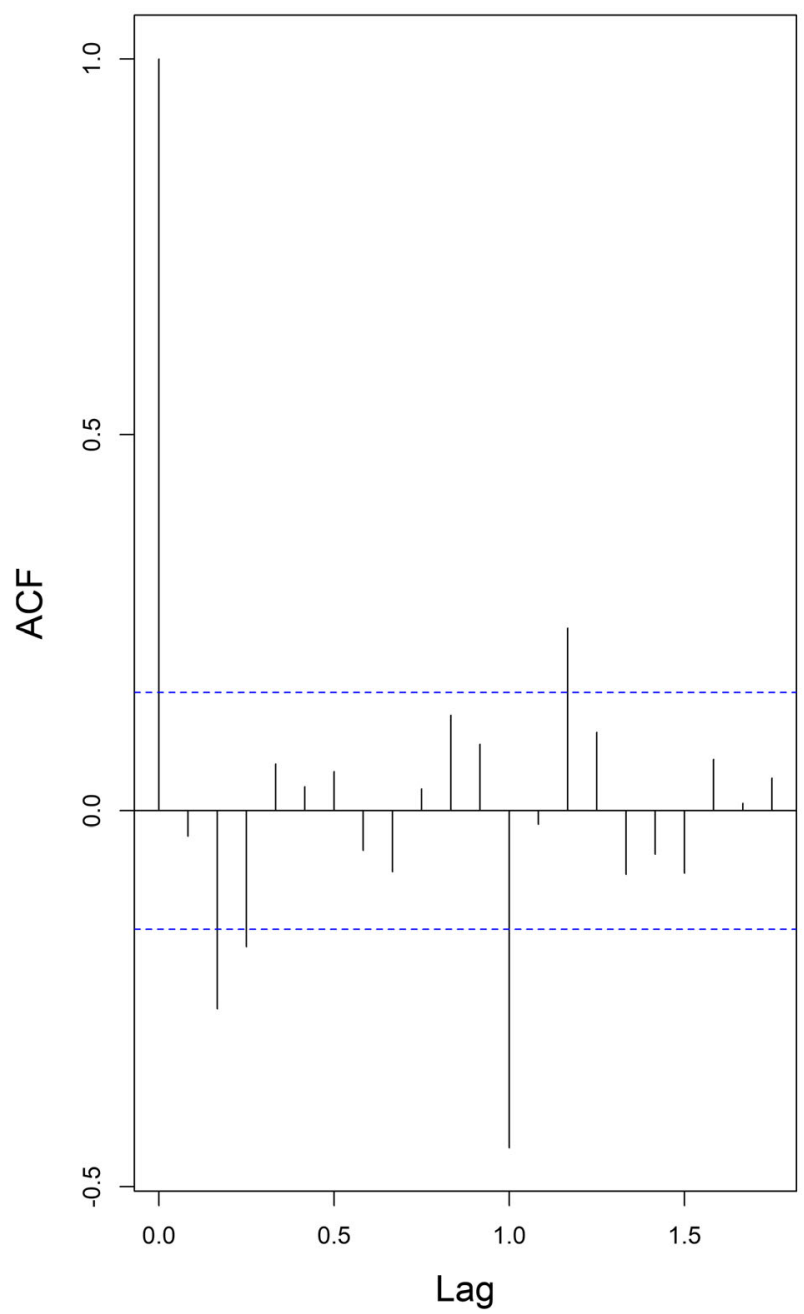

(b)

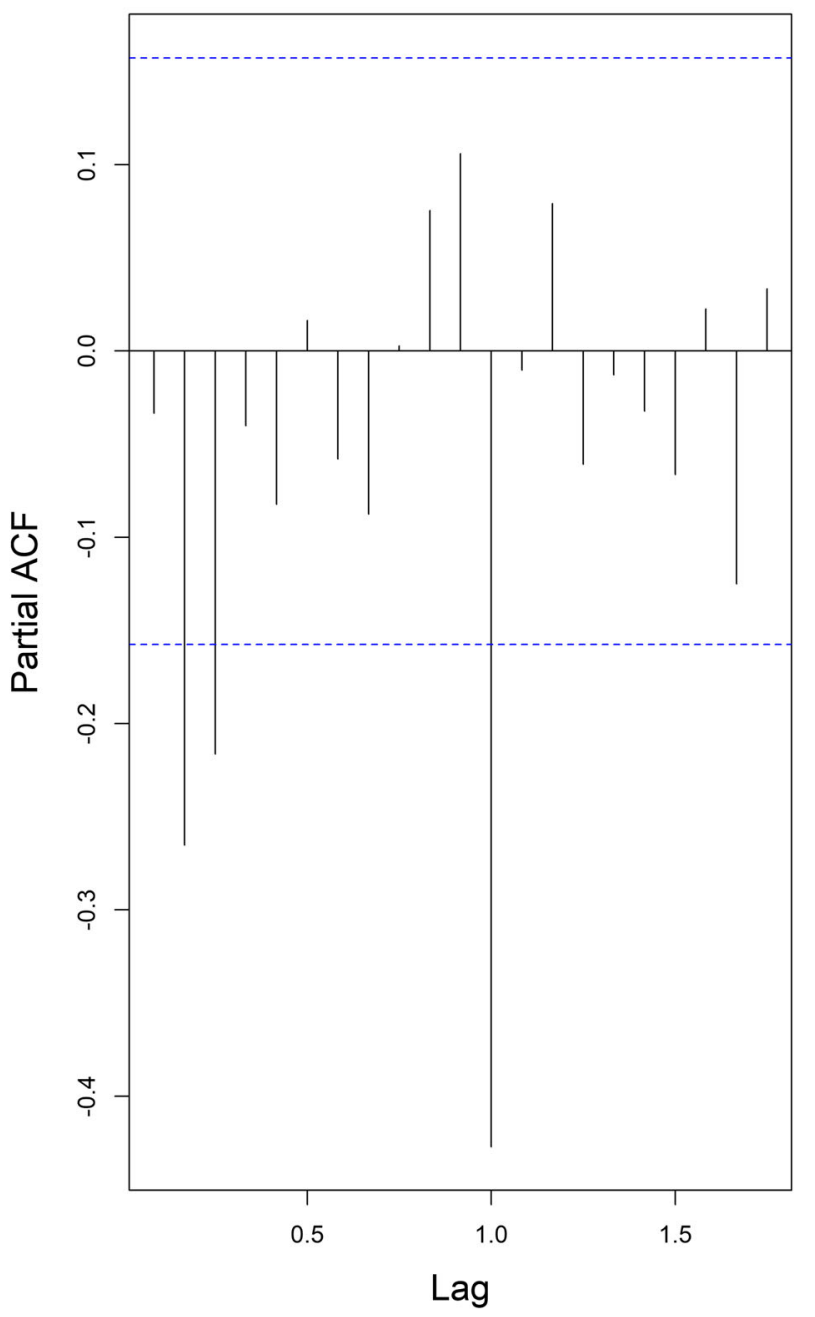

Fig. 5 Autocorrelation function (ACF) and partial ACF charts of monthly mumps incidence numbers. a ACF chart; b Partial ACF chart

good match between the observed value and the fitted value. The incidence of mumps in 2018 peaked from April to June but showed a decreasing trend after June due to the reduction of students' contact during the summer vacation. Thus far, in terms of infectious diseases, the SARIMA model has good results in predicting hand, foot, and mouth disease [31] and tuberculosis [32]. This study is the first to use the SARIMA model to analyze the incidence of mumps in Chongqing. The $\operatorname{SARIMA}(2,1,1) \times(0,1,1)_{12}$ model in this study can well reflect the incidence of mumps in Chongqing, and has a good short-term predictive effect. It can provide
Table 3 AIC values, BIC values, RMSE and MAPE for different SARIMA models

\begin{tabular}{lllll}
\hline & AIC & BIC & \multicolumn{2}{l}{ Goodness of Fits for Models } \\
\cline { 4 - 5 } & & & RMSE & MAPE(\%) \\
\hline SARIMA $(1,1,1)(1,1,0)_{12}$ & 57.34 & 69.52 & 0.2686 & 41.2841 \\
SARIMA $(0,1,2)(1,1,0)_{12}$ & 61.93 & 74.11 & 0.2734 & 44.7352 \\
SARIMA $(1,1,1)(0,1,1)_{12}$ & 34.42 & 46.60 & 0.2450 & 40.5910 \\
SARIMA $(2,1,1)(0,1,1)_{12}$ & 30.05 & 45.27 & 0.2392 & 44.3186 \\
SARIMA $(1,1,2)(0,1,1)_{12}$ & 31.14 & 46.36 & 0.2402 & 43.0071 \\
\hline
\end{tabular}

Table 4 Estimates and standard error of $\operatorname{SARIMA}(2,1,1) \times(0,1$, 1) 12 model parameters

\begin{tabular}{llllll}
\hline Measurements & $\begin{array}{l}\text { Model } \\
\text { Terms }\end{array}$ & Estimates & $\begin{array}{l}\text { Standard } \\
\text { Error }\end{array}$ & t-Value & $\boldsymbol{p}$-Value \\
\hline Non-Seasonality & AR1 term & 0.7186 & 0.1107 & 6.29 & $P<0.05$ \\
& AR2 term & -0.2305 & 0.0878 & 2.63 & $P<0.05$ \\
& MA1 term & -0.8197 & 0.8960 & 9.15 & $P<0.05$ \\
Seasonality & Seasonality & -0.7643 & 0.0694 & 11.01 & $P<0.05$ \\
& MA1 & & & & \\
\hline
\end{tabular}


Table 5 Reported and forecasted incidence of mumps for 2018

\begin{tabular}{lll}
\hline Time (Month) & Actual incidence & Forecasted incidence \\
\hline January 2018 & 2.1885 & 2.0852 \\
February 2018 & 0.6959 & 1.0585 \\
March 2018 & 1.6259 & 1.9447 \\
April 2018 & 2.8616 & 3.2639 \\
May 2018 & 3.1381 & 5.0355 \\
June 2018 & 2.6958 & 4.8205 \\
July 2018 & 1.4959 & 2.9731 \\
August 2018 & 1.0796 & 1.4132 \\
September 2018 & 1.4373 & 1.4198 \\
October 2018 & 1.3203 & 1.6622 \\
November 2018 & 1.5056 & 2.0661 \\
December 2018 & 1.4666 & 2.2634 \\
\hline
\end{tabular}

early warning to health authorities to formulate plans and implement public health intervention measures to prevent and control the disease.

Compared with the ARIMA model, the SARIMA model increases the seasonal effect and is suitable for analyzing sequences with obvious seasons and periodicity [33], while most epidemiological data are seasonal and periodic [32, 34-36]. Compared with other time series analysis methods, The SARIMA model generally adopts the logarithm method, difference method and the seasonal difference method $[37,38]$ to make the series stable without the need for complicated conversion or variable substitution $[39,40]$. In addition, related research shows that among various time series analysis methods, ARIMA is a useful tool for interpreting surveillance data for disease prevention and control [41, 42].

This study has several limitations. We only made short-term predictions. Therefore, various factors

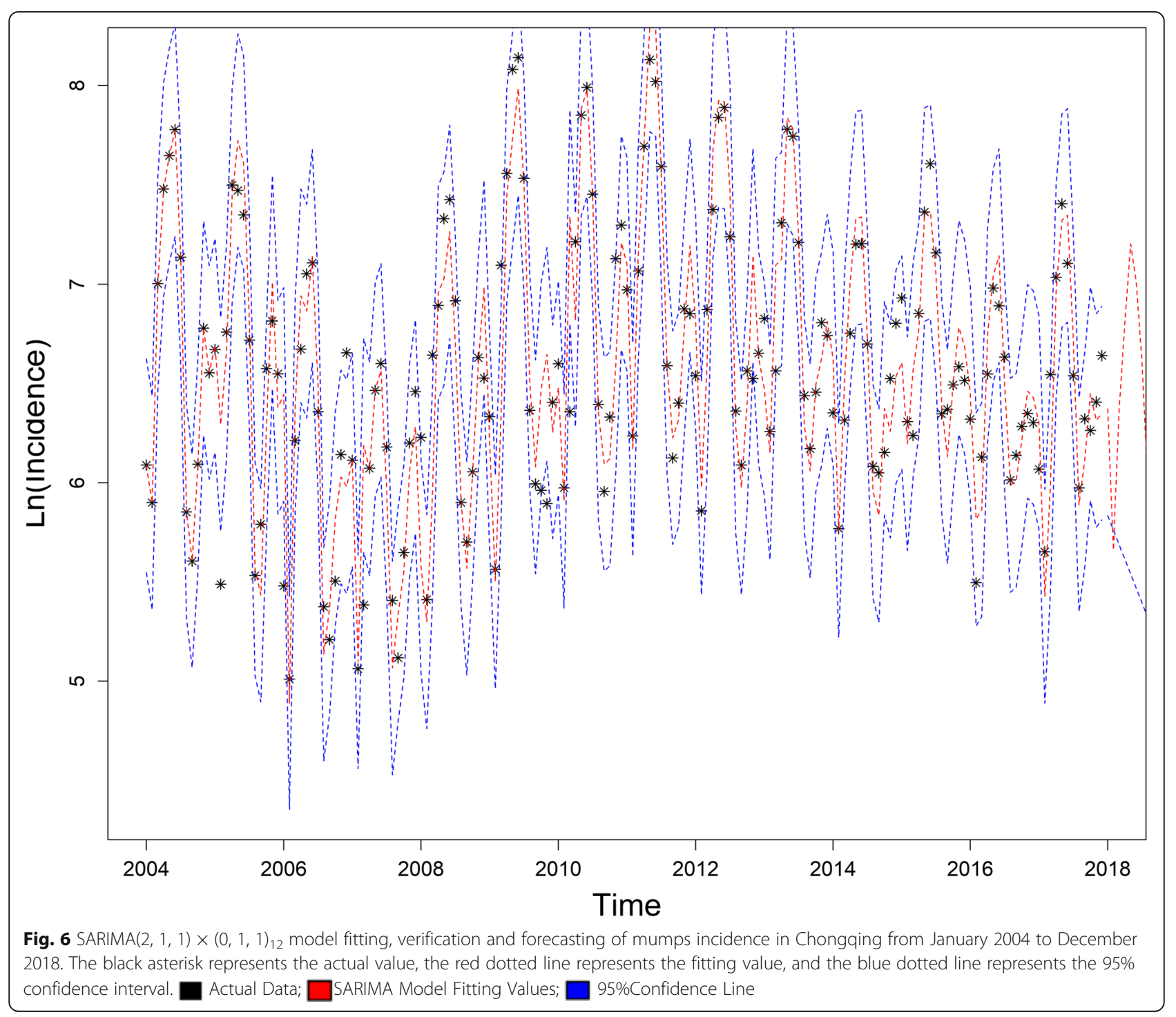


affecting the incidence of mumps should be considered to establish a long-term and stable prediction model. In future research, hybrid models, such as the SARIMANAR hybrid model [43], SARIMA-NARNNX hybrid model [44], and SARIMA-NARX hybrid model [45], can be used to analyze or predict diseases.

\section{Conclusions}

The results of this study suggest that applying the ARIMA time series models to forecast the incidence of mumps is feasible. The confidence intervals of the predicted values contain all the actual values. Thus, the $\operatorname{SARIMA}(2,1,1) \times(0,1,1)_{12}$ model may be used to predict the incidence of mumps. The short-term prediction of mumps is effective, which is helpful for the evaluation of prevention or control measures. Meanwhile, timely and effective countermeasures can be adopted for the epidemic peak that may occur. For instance, the government has strengthened publicity on mumps prevention and control knowledge to improve the public's awareness of the disease.

\section{Abbreviations \\ SARIMA: Seasonal autoregressive integrated moving average; RMSE: Root mean square error; MAPE: The mean absolute percentage error; AIC: Akaike Information Criterion; BIC: Schwarz Bayesian Criterion}

\section{Acknowledgments}

The authors express their thanks to the Chongqing Municipal Center for Disease Control and Prevention for the disease data as well as the help from teachers of Chongqing Medical University.

\section{Authors' contributions}

H.Q.(Hongfang Qiu) and H.Z.(Han Zhao) contributed equally to this paper Conceptualization, M.Y.; Methodology, H.Q. (Hongfang Qiu) and H.Z. (Han Zhao); Software, H.Q. (Hongfang Qiu); Validation, R.O.; Formal analysis, H.Q. (Hongfang Qiu); Investigation, H.Q. (Hongfang Qiu) and H.Z. (Han Zhao); Resources, H.Z. (Han Zhao); Data curation, L.H. and H.Z.; Writing-original draft preparation, H.Q. (Hongfang Qiu); Writing-review and editing, H.Q. (Hongfang Qiu), R.O., H.X. and M.Y.; Visualization, H.Z. and L.H.; Supervision, M.Y., and R.O.; Project administration, M.Y. All authors read and approved the final manuscript.

\section{Funding}

This research received no external funding.

\section{Availability of data and materials}

The data that support the findings of this study are available from the Chongqing Municipal Center for Disease Control and Prevention, but restrictions apply to the availability of these data, which were used under license for the current study, and so are not publicly available. Data are however available from the authors upon reasonable request and with permission of Chongqing CDC.

Ethics approval and consent to participate

Not applicable.

\section{Consent for publication}

Not applicable.

\section{Competing interests}

The authors declare no conflict of interest.

\section{Author details}

1 Department of Epidemiology and Health Statistics, School of Public Health and Management, Chongqing Medical University, Chongqing 400016, China. ${ }^{2}$ Chongqing Municipal Center for Disease Control and Prevention, Chongqing 400042, China. ${ }^{3}$ Department of Medical Informatics Library, Chongqing Medical University, Chongqing 400016, China.

Received: 17 August 2020 Accepted: 3 February 2021

Published online: 17 February 2021

\section{References}

1. Hviid A, Rubin S, Muhlemann K. Mumps. Lancet. 2008;371:932-44.

2. Rubin S, Eckhaus M, Rennick LJ, Bamford CG, Duprex WP. Molecular biology, pathogenesis and pathology of mumps virus. J Pathol. 2015;235:242-52. https://doi.org/10.1002/path.4445.

3. Betakova T, Svetlikova D, Gocnik M. Overview of measles and mumps vaccine: origin, present, and future of vaccine production. Acta Virol. 2013; 57:91-6. https://doi.org/10.4149/av_2013_02_91.

4. Rubin S, Kennedy R, Poland G. Emerging mumps infection. Pediatr Infect Dis J. 2016:35:799-801.

5. KWaKL G. Measles, mumps, rubella vaccine (Priorix ${ }^{\mathrm{TM}}$; GSK-MMR) a review of its use in the prevention of measles, mumps and rubella. Adis Data Inf BV 2003;63:19. https://doi.org/10.2165/00003495-200363190-00012.

6. Kaaijk P, Gouma S, Hulscher HI, Han WG, Kleijne DE, van Binnendijk RS, van Els CA. Dynamics of the serologic response in vaccinated and unvaccinated mumps cases during an epidemic. Hum Vaccin Immunother. 2015;11:175461. https://doi.org/10.1080/21645515.2015.1040967.

7. Ferenczi A, Gee S, Cotter S, Kelleher K, On Behalf Of The Mumps Outbreak Control T. Ongoing mumps outbreak among adolescents and young adults, Ireland, august 2018 to January 2020. Euro Surveill. 2020;25. https://doi.org/1 0.2807/1560-7917.ES.2020.25.4.2000047.

8. Donahue M. Multistate mumps outbreak originating from asymptomatic transmission at a Nebraska wedding — six states, august-October 2019. Morb Mortal Wkly Rep. 2020;69:666-9. https://doi.org/10.15585/mmwr. mm6922a2.

9. Pike J, Marin M, Guo A, Haselow D, Safi H, Zhou F. 2016-2017 Arkansas mumps outbreak in a close-knit community: assessment of the economic impact and response strategies. Vaccine. 2020;38:1481-5. https://doi.org/1 0.1016/j.vaccine.2019.11.066.

10. Cui A, Zhu Z, Hu Y, Deng X, Sun Z, Zhang Y, Mao N, Xu S, Fang X, Gao H, et al. Mumps epidemiology and mumps virus genotypes circulating in mainland China during 2013-2015. PLoS One. 2017;12:e0169561. https://doi. org/10.1371/journal.pone.0169561.

11. Mumps Reported cases by country. Availabe online: https://apps.who.int/ gho/data/view.main.1540_53. (Accessed on 19 Jul 2018).

12. Jiang RJ, Yin QZ, Xu MJ, Zhao ZM, Deng Y, Che YC. Epidemiological characteristics of mumps in mainland China from 2004 to 2018 and key population for prevention and control. Chin J Contemp Pediatr. 2019;21: 441-4. https://doi.org/10.7499/j.issn.1008-8830.2019.05.008.

13. Yu X. Epidemiological features and prevention strategies of mumps in China. Modern Prev Med. 2015;42:2689-91.

14. The National Health Commission, PRC expanded the implementation programme of the National Immunization Program. http://www.gov.cn/ gzdt/2008-02/19/content_893572.htm.

15. Chen DC, Chen ZF, Yang XH, Pan WY, Wang Q, Zhang SH, Zheng NX Huang LF, Zhou Y. Epidemiological and pathogenic characteristics of mumps in Fujian province, 2005-2017. Chin J Epidemiol. 2018;39:1356-61 https://doi.org/10.3760/cmaj.issn.0254-6450.2018.10.013.

16. Wu JB, Ye LX, You EK. Application of ARIMA model in predicting the incidence of infectious diseases. J Math Med. 2007;20:90-2. https://doi.org/1 0.3969/j.issn.1004-4337.2007.01.041.

17. Li JF, Zong Q. The forecasting of the elevator traffic flow time series based on ARIMA and GP. Adv Mater Res. 2012;588-589:1466-71. https://doi.org/1 0.4028/www.scientific.net/AMR.588-589.1466.

18. Kumar V, Mangal A, Panesar S, Yadav G, Talwar R, Raut D, Singh S. Forecasting malaria cases using climatic factors in Delhi, India: a time series analysis. Malar Res Treat. 2014;2014:482851. https://doi.org/10.1155/2014/482 851.

19. Moosazadeh M, Nasehi M, Bahrampour A, Khanjani N, Sharafi S, Ahmadi S. Forecasting tuberculosis incidence in Iran using box-Jenkins models. Iran Red Crescent Med J. 2014;16:e11779. https://doi.org/10.5812/ircmj.11779. 
20. Wang $H$, Tian CW, Wang WM, Luo XM. Time-series analysis of tuberculosis from 2005 to 2017 in China. Epidemiol Infect. 2018;146:935-9. https://doi. org/10.1017/S0950268818001115.

21. Martinez EZ, Silva EASD, Fabbro ALD. A SARIMA forecasting model to predict the number of cases of dengue in Campinas, state of São Paulo, Brazil. Rev Soc Bras Med Trop. 2011;44:436-40. https://doi.org/10.1590/S003 7-86822011000400007.

22. Lin Y, Chen M, Chen G, Wu X, Lin T. Application of an autoregressive integrated moving average model for predicting injury mortality in Xiamen, China. BMJ Open. 2015:5. https://doi.org/10.1136/bmjopen-2015-008491.

23. Picardeau $M$, et al. Burden of disease measured by disability-adjusted life years and a disease forecasting time series model of scrub typhus in Laiwu, China. PLoS Negl Trop Dis. 2015;9:e3420. https://doi.org/10.1371/journal. pntd.0003420

24. Fei FR, Feng LZ, Xu Z, Feng ZJ. Epidemiology of mumps in China, 20082010. Surveill Infect Dis. 2011;26:691-3. https://doi.org/10.3784/j.issn.10039961.2011.09.008.

25. Qiu H, Zeng D, Yi J, Zhu H, Hu L, Jing D, Ye M. Forecasting the incidence of acute haemorrhagic conjunctivitis in Chongqing: a time series analysis. Epidemiol Infect. 2020;148:e193.

26. Peng Z-X. ARIMA multiplicative seasonal module and its application in the prediction of infectious diseases. Appl Stat Manag. 2008;27:362-8. https:// doi.org/10.13860/j.cnki.sltj.2008.02.009

27. Cao S, Wang F, Tam W, Tse LA, Kim JH, Liu J, Lu Z. A hybrid seasonal prediction model for tuberculosis incidence in China. BMC Med Inform Decis Mak. 2013;13:56. https://doi.org/10.1186/1472-6947-13-56.

28. Mohammed SH, Ahmed MM, Al-Mousawi AM, Azeez A. Seasonal behavior and forecasting trends of tuberculosis incidence in holy Kerbala, Iraq. Int J Mycobact. 2018;7:361-7. https://doi.org/10.4103/ijmy.ijmy_109_18.

29. Zhu H, Zhao H, Qu R, Xiang HY, Hu L, Jing D, Sharma M, Ye ML. Epidemiological characteristics and spatiotemporal analysis of mumps from 2004 to 2018 in Chongqing, China. Int J Environ Res Public Health. 2019;16: 3052. https://doi.org/10.3390/ijerph16173052.

30. Su QR, Liu J, Ma C, Fan CX, Wen N, Luo HM, et al. Epidemic profile of mumps in China during 2004-2013. Zhonghua yu fang yi xue za zhi [Chin J Prev Med]. 2016;50(7):611-4. https://doi.org/10.3760/cma.j.issn.0253-9624.201 6.07.009.

31. Tian CW, Wang H, Luo XM. Time-series modelling and forecasting of hand, foot and mouth disease cases in China from 2008 to 2018. Epidemiol Infect. 2019:147:e82.

32. Mao Q, Kai Z, Wu Y, Chaonan C. Forecasting the incidence of tuberculosis in China using the seasonal auto-regressive integrated moving average (SARI MA) model. J Infect Public Health. 2018;11:707-12. https://doi.org/10.1016/j. jiph.2018.04.009

33. Valipour M. Long-term runoff study using SARIMA and ARIMA models in the United States. Meteorol Appl. 2015;22:592-8 [CrossRef].

34. Wang Y, Xu C, Zhang S, Yang L, Wang Z, Zhu Y, Yuan J. Development and evaluation of a deep learning approach for modeling seasonality and trends in hand-foot-mouth disease incidence in mainland China. Sci Rep. 2019;9: 8046. https://doi.org/10.1038/s41598-019-44469-9.

35. Cong J, Ren M, Xie S, Wang P. Predicting seasonal influenza based on SAR MA model, in mainland China from 2005 to 2018. Int J Environ Res Public Health. 2019;16. https://doi.org/10.3390/ijerph16234760.

36. Liu H, Li C, Shao Y, Zhang X, Zhai Z, Wang X, Qi X, Wang J, Hao Y, Wu Q, Jiao M. Forecast of the trend in incidence of acute hemorrhagic conjunctivitis in China from 2011-2019 using the seasonal autoregressive integrated moving average (SARIMA) and exponential smoothing (ETS) models. J Infect Public Health. 2020;13:287-94. https://doi.org/10.1016/j. jiph.2019.12.008.

37. Li RZ, Zhang T, Liang YM, Luo C, Jiang Z, Xue FZ, Liu YZ, Liu J, Li XJ. Application of SARIMA model in the prediction of mumps. J Shandong Univ (Medical Edition). 2016;54:82-6. https://doi.org/10.6040/j.issn.1671-7554.0.201 5.1163.

38. Gharbi M. Time series analysis of dengue incidence in Guadeloupe, French West Indies: forecasting models using climate variables as predictors. BMC Infect Dis. 2011;11:166. https://doi.org/10.1186/1471-2334-11-166.

39. Liu X, Jiang B, Bi P, Yang W, Liu Q. Prevalence of haemorrhagic fever with renal syndrome in mainland China: analysis of National Surveillance Data, 2004-2009. Epidemiol Infect. 2012;140:851-7. https://doi.org/10.1017/S09502 68811001063 .
40. Shumway RH, Stoffer DS. Time series analysis and its applications: with R examples. 3th ed. New York: Springer; 2011. p. 83e162.

41. Ma L, Tian F. Application of time series analysis in the prediction of hypertension incidence. Chin J Gerontol. 2010;30:1777-80.

42. Feng H, Duan G, Zhang R, Zhang W. Time series analysis of hand-footmouth disease hospitalization in Zhengzhou: establishment of forecasting models using climate variables as predictors. PLoS One. 2014;9(1):e87916.

43. Wang Y, Xu C, Wang Z, Zhang S, Zhu Y, Yuan J. Time series modeling of pertussis incidence in China from 2004 to 2018 with a novel wavelet based SARIMA-NAR hybrid model. PLoS One. 2018;13:e0208404. https://doi.org/1 0.1371/journal.pone.0208404.

44. Wang Y, Xu C, Zhang S, Wang Z, Yang L, Zhu Y, Yuan J. Temporal trends analysis of tuberculosis morbidity in mainland China from 1997 to 2025 using a new SARIMA-NARNNX hybrid model. BMJ Open. 2019;9:e024409. https://doi.org/10.1136/bmjopen-2018-024409.

45. Wang Y, Xu C, Wang Z, Yuan J. Seasonality and trend prediction of scarlet fever incidence in mainland China from 2004 to 2018 using a hybrid SARI MA-NARX model. PeerJ. 2019;7:e6165. https://doi.org/10.7717/peerj.6165.

\section{Publisher's Note}

Springer Nature remains neutral with regard to jurisdictional claims in published maps and institutional affiliations.
Ready to submit your research? Choose BMC and benefit from:

- fast, convenient online submission

- thorough peer review by experienced researchers in your field

- rapid publication on acceptance

- support for research data, including large and complex data types

- gold Open Access which fosters wider collaboration and increased citations

- maximum visibility for your research: over $100 \mathrm{M}$ website views per year

At BMC, research is always in progress.

Learn more biomedcentral.com/submissions 